$\Phi=-1$

\title{
Analysis and modeling of standalone wind driven doubly fed induction generator
}

\author{
Prerak Bhardwaj ${ }^{1 *}$, Vijayakumar $\mathbf{K}^{2}$ \\ ${ }^{1,2}$ Department of Electrical Engineering, Malaviya National Institute of Technology, JLN Marg, Jaipur, India 302017 \\ *Corresponding author E-mail: prerakbhardwaj@gmail.com
}

\begin{abstract}
This paper briefly enlightens on the analysis and modeling aspects of the standalone operation of doubly fed induction generator (DFIG) based wind energy conversion system (WECS). The DFIG in WECS is controlled via a single converter on the rotor terminals. The battery at the converter terminal fulfills the active/reactive power demand of the load. Whereas, the incorporation of the speed estimation technique makes the WECS free from the complexities associated with the speed sensors, thus provide a robust and reliable operation. The control technique used is simple and based on controlling the stator voltage and frequency by their comparison with a reference voltage and frequency using a simple PI controller. The supportive results for the analysis and modelling has been presented for a $7.5 \mathrm{~kW}$ wound rotor induction generator in MATLAB/Simulink environment.
\end{abstract}

Keywords: Speed Estimation; Rotor Side Converter; Wind Energy Conversion System; Renewable Energy

\section{Introduction}

In the present scenario, the concern regarding the environmental pollution is at its utmost verge. The conventional energy sources are main emission sources, therefore the alternate solutions in form of the integration of the renewable sources are finding more advantageous as they are emission less, sustainable and reliable. The rise in the renewable energy sources also helps in raising the economy of the country. The total installed capacity of India has reached to $310 \mathrm{GW}$, out of which renewables have $14.8 \%$ generation share.

However, it has been reported that in last five years, around $20 \%$ growth of renewables occurred accounting from 14.4 GW in 2009 to $50.6 \mathrm{GW}$ till Dec. 2016. Among all the renewables, wind energy witnessed to be leading with $57.4 \%$ of installed capacity $(28.7 \mathrm{GW})$ followed by other renewable energy sources as shown in the Table 1 [1][2]. The wide speed variability in the wind speed makes the DFIG a preferable choice due to the wide operation range $( \pm 30 \%)$ near synchronous speed, low rated (1/3) converter operation, lower rated filter requirement, maximum power extraction and higher output efficiency.

Table 1: Total power installed capacity in India

\begin{tabular}{cccc}
\multicolumn{4}{c}{ Table 1: Total power installed capacity in India } \\
\begin{tabular}{cccc}
\multicolumn{4}{c}{ Conventional (85.2\%) } \\
\hline Thermal & Hydro & Nuclear & Renewable \\
\hline $69.40 \%$ & $13.90 \%$ & $1.90 \%$ & $14.80 \%$ \\
\hline \multicolumn{4}{c}{ Renewable $(14.80 \%)$} \\
\hline Solar & Biomass & Small Hydro & Wind \\
\hline $2.64 \%$ & $2.36 \%$ & $1.33 \%$ & $8.43 \%$ \\
\hline
\end{tabular}
\end{tabular}

To adjust with the intermittency of the wind, the DFIG operates in sub-synchronous mode and super-synchronous mode. If the wind speed is higher comparative to input power, the DFIG operates in super-synchronous mode and the output power is obtained both from the stator and rotor terminals. However, if the wind speed is less or not sufficient enough to generate the input power, the converter on the rotor side is utilized to feed the extra power. Thus, the operation exhibits under sub-synchronous mode [3][4]. In this way, the DFIG utilizes the variations in wind more effectively comparative to other generators. Fig. 1 shows the conventional topology of the DFIG having back connected converter configuration for the autonomous control of active and reactive power, and unity power factor operation. The vector control technique is used for the desired operation in back to back connected converter topology [5][8].

The DFIG has been extensively utilized both in grid connected and standalone operation for WECS. In grid connected mode, the reactive power requirement is fulfilled from the grid itself therefore, power flow control is the only concern. While, in standalone operation, the regulation of the stator terminal voltage and frequency is required.

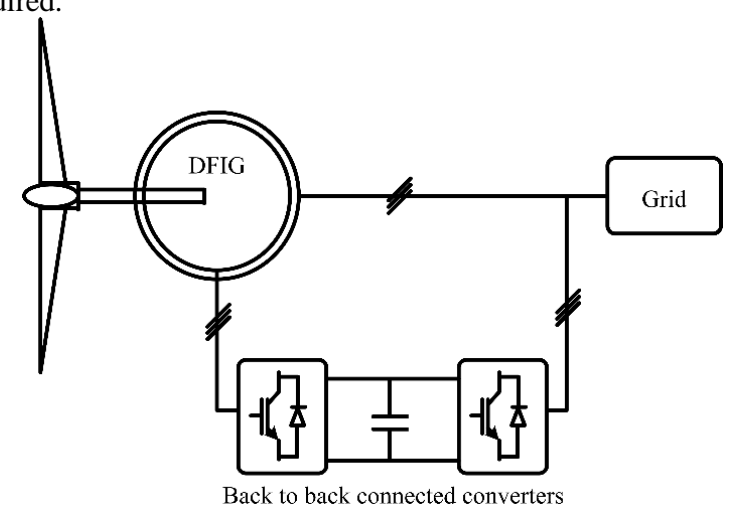

Fig. 1: Conventional topology of DFIG using back connected converters configuration

Recently, the single converter on the rotor side topology of DFIG catches the attraction of the researchers, the only requirement is the battery at dc terminal of the converter. The battery bank is used as a continuous and reliable source in standalone system for 
providing the required magnetization to the machine as well as removes the fluctuations from the output power [9][10]. Furthermore, a suitable control technique is required that should takes care of the variations in stator voltage and frequency, and fluctuations occurring during the change in load and wind speed. Many researchers suggested different control techniques based on vector control, direct torque control, direct power control [11]-[14]. These techniques require the complex transformations of current, voltage in the different reference frames (synchronous, stationary, and rotor). Moreover, the precise information of the current in the rotor winding is required to manage the variations in the wind speed and load. The accurate knowledge of the generator rotor position is required to estimate the suitable value of the current flowing in the rotor terminal. Further, in [15] the rotor position estimation technique is presented for the nonlinear loads. The rotor position or speed estimation techniques are more advantageous in compare to methods based on using the sensors due to less maintenance, reliable and cost effective solution [16]-[20]. This paper discusses the modeling aspects along with the analysis of the DFIG for the variation in the mechanical input by using speed sensorless technique, and presents the simulated results in the MATLAB environment. The winding of the rotor is excited through a single voltage source converter (VSC) having battery connected on its dc terminal as shown in fig. 2. The charging and discharging of the battery depends on the operating mode. The charging will be taken place via the feedback diodes connected across the switches in the inverter. Section II discusses the detailed modeling aspects of DFIG, wind turbine, converter rating and speed estimation technique in form of mathematical equations. The control technique is discussed in the section III and the analysis of the system through simulations results in section IV. The V section includes the conclusion based on the simulated work.

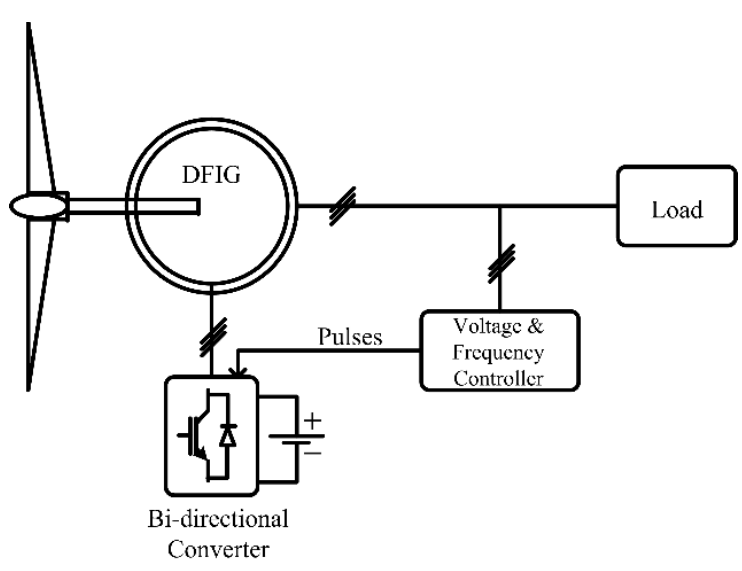

Fig. 2: Topology of DFIG with single converters on the rotor side

\section{Mathematical modelling of the system}

The mathematical modelling of the system consist of the modelling of the wind turbine, DFIG and battery voltage calculation.

\subsection{Modelling of the wind turbine}

The energy available from the wind stream $\left(P_{\text {air }}\right)$ is as follows

$P_{\text {air }}=\frac{1}{2} \rho_{\text {air }} S V_{\text {air }}^{3}$

Where, $\rho_{a i r}$ - air density, $V_{\text {air }}$ - wind speed in $\mathrm{m} / \mathrm{s}$, and $S$ - area swept by turbine blades in $\mathrm{m}^{2}$.

The relation for the power $\left(P_{m}\right)$ output from the wind turbine is

$P_{m}=C_{p}(\lambda, \beta) P_{\text {air }}$

Where, the power coefficient $\left(C_{p}\right)$ are governed by tip speed ratio $(\lambda)$ and by pitch angle $(\beta)$. The $\lambda$ is defined as follows
$\lambda=\frac{R * \omega_{r}}{V_{\text {air }}}$

Where, $R$ - radius of rotor, $\omega_{r}-$ aerodynamic rotor speed

The pitch angle is considered as zero. Therefore, the equation of $C_{p}$ is as follows

$C_{p}=0.5176\left(\frac{116}{\lambda_{i i}}-0.4 \beta-5\right) e^{-21 / \lambda_{i i}}+0.0068 \lambda$

Where,

$$
\lambda_{i i}=\left(\frac{1}{\frac{1}{\lambda+0.08 \lambda}+\frac{0.035}{\beta^{3}+1}}\right)
$$

\subsection{Modelling of the DFIG}

The DFIG stator and rotor voltages along d-axis and q-axis in synchronous reference frame is as follows

$$
\begin{aligned}
& V_{d s s}=R_{s} i_{d s s}+\frac{d \phi_{d s s}}{d t}-\omega_{e} \phi_{q s s} \\
& V_{q s s}=R_{s} i_{q s s}+\frac{d \phi_{q s s}}{d t}-\omega_{e} \phi_{d s s} \\
& V_{d r r}=R_{s} i_{d r r}+\frac{d \phi_{d r r}}{d t}-\left(\omega_{e}-\omega_{r}\right) \phi_{q r r} \\
& V_{q r r}=R_{s} i_{q r r}+\frac{d \phi_{q r r}}{d t}+\left(\omega_{e}-\omega_{r}\right) \phi_{d r r}
\end{aligned}
$$

The flux linkages are as follows

$$
\begin{aligned}
& \phi_{d s s}=L_{s s} i_{d s s}+L_{m m} i_{d r r} \\
& \phi_{q s s}=L_{s s} i_{q s s}+L_{m m} i_{q r r} \\
& \phi_{d r r}=L_{r r} i_{d r r}+L_{m m} i_{d s s} \\
& \phi_{q r r}=L_{r r} i_{q r r}+L_{m m} i_{q s s}
\end{aligned}
$$

The expression for the electromagnetic developed torque and torque balance equation is as follows

$T_{e m}=\frac{P}{2}\left(\phi_{d s s} i_{q s s}-\phi_{q s s} i_{d s s}\right)$

$T_{m}-T_{e m}=J \frac{d \omega_{m}}{d t}$

Where, $\left(V_{d s s}, V_{q s s}, V_{d r r}, V_{q r r}\right)$ - stator and rotor voltages along d and q-axis, $\left(i_{d s s}, i_{q s s}, i_{d r r}, i_{q r r}\right)$ - stator and rotor current along $\mathrm{d}$ and q-axis, $\phi$ - flux linkage, $\left(R_{s}, R_{r}\right)$ - resistances of stator and rotor winding per phase, $\left(\omega_{e}, \omega_{r}\right)$ - stator and rotor angular frequency, $\left(L_{s s}, L_{r r}, L_{m m}\right)$ - stator, rotor and magnetizing inductances per phase, $P$ - number of pole pair, $T_{m}$ - mechanical input torque and $T_{e m}$ - electromagnetic developed torque.

\subsection{Calculation of battery voltage}

The expression of battery voltage is as follows

$V_{b}=\frac{2 \sqrt{2}}{\sqrt{3}} \frac{1}{m_{i}} V_{r}$

Where,

$V_{r}$ - phase voltage of the rotor and

$m_{i}-$ modulation index 


\section{Control Strategy}

The operation of the standalone DFIG is complex due to the precise control requirement from both the turbine and rotor side converter. The mechanical controlling of the wind turbine requires lot of investment to detect the sufficient pitch angle for the blades for the optimized power input from the wind turbine. Hence, it is quite advantageous to do the controlling of the DFIG from the rotor side. Therefore the slip frequency currents from the rotor are injected/drawn to maintain the operation of the DFIG from the rotor side inverter. Basically in standalone systems, the utmost requirement is to uphold the stator winding voltage and frequency persistent to their rated values. This paper utilizes the real stator voltage and frequency and compares it with a reference value of the stator voltage and frequency i.e. $380 \mathrm{~V}$ and $50 \mathrm{~Hz}$. The error generated after comparison is regulated via a PI controller which provides the necessary forcing function to minimize the variation occurred in the voltage and frequency of the stator winding. The output after the PI controller is sent to the rate limiter, which settle the responses in a suitable range. The limiter output signal in frequency governing loop is utilized to generate sine wave of unit amplitude and being multiplied further with the output signal of the limiter obtained from voltage governing loop, thus modulating signal gets generated. Further, the comparator is used to compare the modulating signal with the unit amplitude carrier (triangular) signal of $1 \mathrm{kHz}$ frequency. The switching signals generated after comparison are used for generating the control signal (in form of rotor current) for the rotor winding. Therefore, for any variation in the wind speed and load, the control signal for the rotor terminals is generated as shown in fig. 3. The speed estimation technique is also incorporated in the system to relieve it from the noise occurring due to speed sensors. In addition, the reduction in hardware complexity and the cost is achieved.

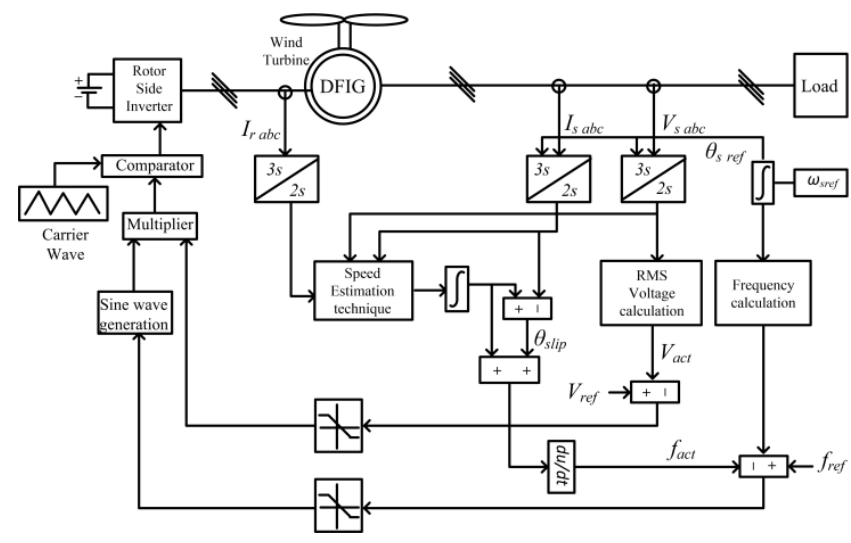

Fig. 3: Control strategy for the standalone operation

Fig. 4 shows the block diagram for speed estimation requiring the voltage $\left(V_{s a b c}\right)$ and current $\left(I_{s a b c}\right)$ of stator terminal, and only current $\left(I_{r a b c}\right)$ from the rotor terminal as input components. The required components are converted into the two phase synchronously rotating reference frame as shown below.

$I_{r}=\left(I_{r a}+j I_{r b}\right)$

$I_{s}=\left(I_{s a}+j I_{s b}\right)$

$V_{s}=\left(V_{s a}+j V_{s b}\right)$

The unit vectors obtained after resolving the rotor current in rotor reference frame is as shown in equation (11). Then, the obtained current of the rotor again transformed into the stationary reference frame by using the magnetizing current component and stator current component as shown in equation (12)

$$
\begin{aligned}
& \operatorname{Sin}\left(\theta_{2}\right)=\frac{I_{r a}}{\sqrt{I_{r a}^{2}+I_{r b}^{2}}} \\
& \operatorname{Cos}\left(\theta_{2}\right)=\frac{I_{r b}}{\sqrt{I_{r a}^{2}+I_{r b}^{2}}} \\
& I_{r a 1}=I_{m s a}-\left(1+\sigma_{s}\right) I_{s a} \\
& I_{r b 1}=I_{m s b}-\left(1+\sigma_{s}\right) I_{s b}
\end{aligned}
$$

Where, magnetizing current $I_{m s}$ is as follows

$$
I_{m s}=\frac{V_{s}}{\omega_{s} L_{m}}
$$

This value of magnetizing current is used initially, then it will be calculated by changing the real time value of the rotor current into the stationary coordinates by means of the unit vectors generated in the previous interval.

Further, the unit vector along the stationary reference frame is as

$$
\begin{aligned}
& \operatorname{Sin}\left(\theta_{1}\right)=\frac{I_{r a 1}}{\sqrt{I_{r a 1}^{2}+I_{r b 1}^{2}}} \\
& \operatorname{Cos}\left(\theta_{1}\right)=\frac{I_{r \beta 1}}{\sqrt{I_{r a 1}^{2}+I_{r b 1}^{2}}}
\end{aligned}
$$

Now, the variation obtained between the stator and rotor angle is used to calculate the rotor position $(\varepsilon)$. However, the unit vectors are calculated as follows

$$
\begin{aligned}
& \operatorname{Sin}(\varepsilon)=\operatorname{Sin}\left(\theta_{1}\right) \operatorname{Cos}\left(\theta_{2}\right)-\operatorname{Sin}\left(\theta_{2}\right) \operatorname{Cos}\left(\theta_{1}\right) \\
& \operatorname{Cos}(\varepsilon)=\operatorname{Cos}\left(\theta_{1}\right) \operatorname{Cos}\left(\theta_{2}\right)+\operatorname{Sin}\left(\theta_{1}\right) \operatorname{Sin}\left(\theta_{2}\right)
\end{aligned}
$$

Therefore, the rotor speed can be estimated as follows

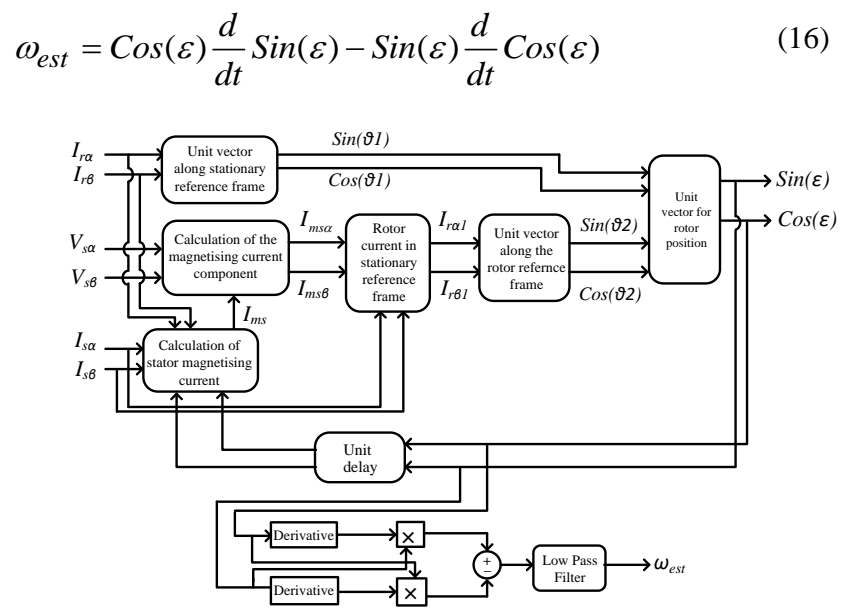

Fig. 4: Block diagram for rotor position estimation technique

\section{Results and discussion}

The $7.5 \mathrm{~kW}$ DFIG system is used for the WECS controlled via a single converter and simulated in the MATLAB/Simulink. Details of the DFIG parameters are given in Appendix - 1. Initially, the mechanical power input from the wind turbine is $7.55 \mathrm{~kW}$ and the output power is $7.35 \mathrm{~kW}$ as shown in fig. 5. Various simulated responses of stator current $\left(\mathrm{I}_{\mathrm{S} \text { abc }}\right)$, rotor speed $\left(\mathrm{W}_{\mathrm{r}}\right)$, developed torque $\left(\mathrm{T}_{\mathrm{em}}\right)$ and rotor current $\left(\mathrm{I}_{\mathrm{r}} \mathrm{abc}\right)$ are shown in fig. 6 . 


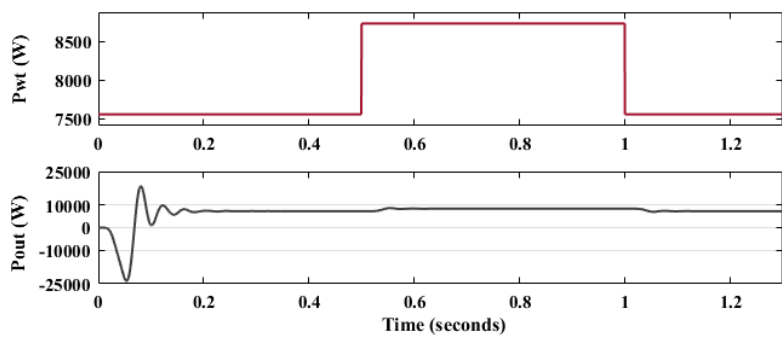

Fig. 5: Response of power output $\left(\mathrm{P}_{\text {out }}\right)$ from DFIG due to variation in input power $\left(\mathrm{P}_{\mathrm{wt}}\right)$

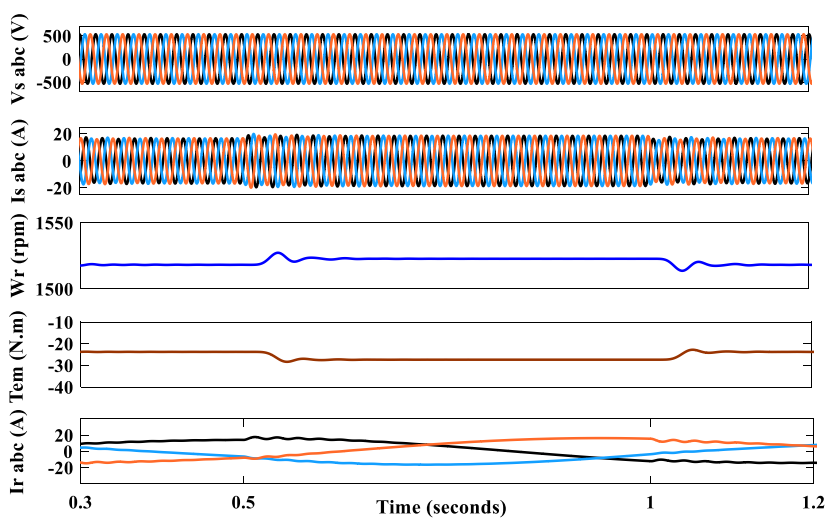

Fig. 6: Response of stator voltage $\left(V_{\mathrm{s} \text { abc }}\right)$, stator current $\left(\mathrm{I}_{\mathrm{s}}\right.$ abc $)$, rotor speed $\left(\mathrm{W}_{\mathrm{r}}\right)$, developed torque $\left(\mathrm{T}_{\mathrm{em}}\right)$ and rotor current $\left(\mathrm{I}_{\mathrm{r}}\right.$ abc $)$ during variation in input power

The voltage and frequency error response indicate that the desired stator voltage and frequency is well maintained i.e. at $380 \mathrm{~V}$ and $50 \mathrm{~Hz}$. The variation in the mechanical input power is made at $\mathrm{t}_{1}=$ $0.5 \mathrm{sec}$ and the input power is varied from $7.55 \mathrm{~kW}$ to $8.72 \mathrm{~kW}$ and restored back to $7.55 \mathrm{~kW}$ at $\mathrm{t}_{2}=1 \mathrm{sec}$. Due to variation in input power, the output power of the DFIG is varied from 7.35 $\mathrm{kW}$ to 8.45 at $\mathrm{t}_{1}=0.5 \mathrm{sec}$ and restored back to $7.35 \mathrm{~kW}$ at $\mathrm{t}_{2}=1$ sec. It has been observed from the results that the stator current, rotor speed, and rotor current increase. However, the developed torque gets increase in the negative direction. During the span of variation in the mechanical input power, the stator terminals voltage and frequency remain preserved at their rated values. Thus, the voltage and frequency controller perform quite good for maintaining the variation as seen from fig. 7.

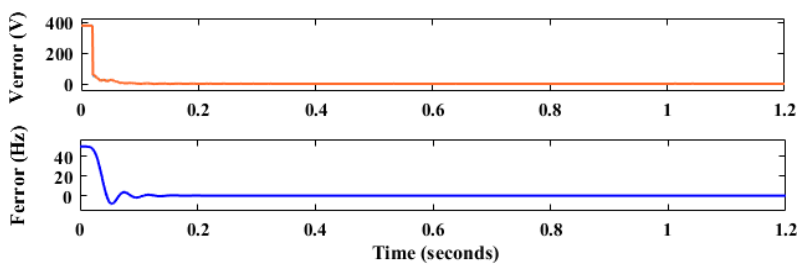

Fig. 7: Response of the voltage error $\left(\mathrm{V}_{\text {error }}\right)$ and frequency error $\left(\mathrm{F}_{\text {error }}\right)$ during variation in the input power

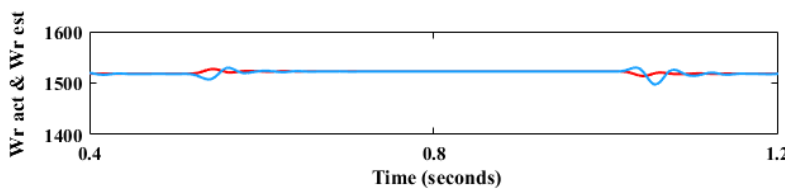

Fig. 8: Tracking performance of the estimated speed $\left(\mathrm{W}_{\mathrm{r} \text { est }}\right)$ to the actual speed $\left(\mathrm{W}_{\mathrm{r}}\right.$ ) during variation in the input power

Fig. 8. indicates the tracking performance of the speed estimator. The technique used is quite efficient to track the actual speed during the variations in the mechanical input. Within 2 cycles, the estimator is capable to track the actual speed. Thus, the system can be easily used for high performance drives where the mounting of the speed sensors produces noise in the system, and the complexity in mounting also remains an issue of concern.

\section{Conclusion}

This paper has attempted to present an analysis of the standalone DFIG for the variation in the wind speed using single converter on the rotor side having battery on its dc terminals. The simulated results indicate that the voltage and frequency governing loops are able to maintain the voltage and frequency at stator terminals. The voltage and frequency error during the variation in the mechanical input also verify the precision of the controller. The simulated results exactly match with the analysis used for the work. The standalone system can be used for electrification of villages where grid supply remains unapproachable. The future work includes the performance analysis of the proposed system with the different electrical and mechanical loadings.

\section{Acknowledgement}

Authors wish to thank science and engineering research board (SERB), department of science and technology (DST), for the project reference number YSS/2015/001473 and Department of Electronics and Information Technology (DeitY) for YFRF scheme.

\section{References}

[1] MNRE, “Annual Report 2016-2017 [Online]. Available http://mnre.gov.in/file-manager/annual-report/2."

[2] MNRE, “Annual Report 2016-2017 [Online]. Available: http://mnre.gov.in/file-manager/annual-report/20162017/EN/pdf/3.pdf.'

[3] Vijayakumar K, Kumaresan N, Gounder N, \& Gounden A (2013), Operation of inverter-assisted wind-driven slip-ring induction generator for stand-alone power supplies. IET Electric Power Applications 7, 256-269.

[4] Carrasco G, Silva CA, Peña R, \& Cárdenas R (2015), Control of a four-leg converter for the operation of a DFIG feeding stand-alone unbalanced loads. IEEE Transaction on Industrial Electronics 62(7), 4630-4640.

[5] Pena R, Clare JC, \& Asher GM (1996), A doubly fed induction generator using back-to-back PWM converters supplying an isolated load from a variable speed wind turbine. IEE Proceedings Electric Power Applications 143(5), 380-387.

[6] Portillo RC, Prats MM, Leon JI, Sánchez JA, Carrasco JM, Galván E, \& Franquelo LG (2006), Modeling strategy for back-to-back three-level converters applied to high-power wind turbines. IEEE Transaction on Industrial Electronics 53(5), 1483-1491.

[7] Kawabata Y \& Ejiogu E (1999), Vector-controlled double-inverterfed wound-rotor induction motor suitable for high-power drives. IEEE Transaction on Industrial Electronics 35(5), 1058-1066.

[8] Jabr HM, \& Kar NC,"Adaptive vector control for slip energy recovery in doubly-fed wind driven induction generator", Proceedings of the Canadian Conference on Electrical and Computer Engineering, (2005), pp: 759-762.

[9] Vijayakumar K, Kumaresan N, Gounden N (2012), Operation and closed-loop control of wind-driven stand-alone doubly fed induction generators using a single inverter-battery system. IET Electric Power Applications 6(3), 162-171.

[10] Naidu NK \& Singh B (2016), Experimental implementation of a doubly fed induction generator used for voltage regulation at a remote location. IEEE Transaction on Industrial Applications 52(6), 5065-5072.

[11] Naidu NK \& Singh B (2012), Direct power control of single VSC based DFIG without rotor position sensor. IEEE Transaction on Industrial Applications 50(6), 4152-4163.

[12] Sharma S, \& Singh B (2010), Isolated wind energy conversion with asynchronous generator for rural electrification. Proceedings of the Power Electronics, Drives and Energy Systems, (2010), pp: 1-7.

[13] Gundavarapu A, Misra H, \& Jain AK (2017), Direct torque control scheme for DC voltage regulation of the standalone DFIG-DC system. IEEE Transaction on Industrial Electronics 64(5), 3502-3512.

[14] X. Lie \& P. Cartwright (2006), Direct active and reactive power control of DFIG for wind energy generation. IEEE Transaction on Energy Conversion 21(3), 750-758.

[15] Jain AK \& Ranganathan VT (2008), Wound rotor induction generator with sensorless control and integrated active filter for feeding 
nonlinear loads in a stand-alone grid. IEEE Transaction on Industrial Electronics, 55(1), 218-228.

[16] Vijayakumar K, Kumaresan N, and Gounden NA (2015), Speed sensor-less maximum power point tracking and constant output power operation of wind-driven wound rotor induction generators. IET Power Electronics 8, 33-46.

[17] A. K. Jain,"Control of stand-alone variable speed generation system using wound rotor induction machine", M.S. thesis, Indian Institute of Science Bangalore, 2004.

[18] Abdellatif M, Debbou M, Slama-Belkhodja I, \& Pietrzak-david M (2014), Simple low-speed sensorless dual DTC for double fed induction machine drive. IEEE Transaction on Industrial Electronics 61(8), 3915-3922.

[19] Drive I, Poddar G, \& Ranganathan VT (2006), Sensorless doubleinverter-fed wound-rotor. IEEE Transaction on Industrial Electronics 53(1), 86-95.

[20] Bayhan S, Abu-rub H, \& Ellabban O (2016), Sensorless model predictive control scheme of wind-driven doubly fed induction generator in de microgrid. IET Renewable Power Generation. 10(4), 514521.

\section{APPENDIX-1}

\begin{tabular}{|l|l|}
\hline DFIG Details & Rating \\
\hline Power Rating & $7.5 \mathrm{KVA}$ \\
\hline Voltage Rating & $380 \mathrm{~V}(\mathrm{RMS})$ \\
\hline Frequency Rating & $50 \mathrm{~Hz}$ \\
\hline Pole pairs & 2 \\
\hline Resistance of stator winding $\left(\mathrm{R}_{\mathrm{s}}\right)$ & $0.416 \mathrm{ohm}$ \\
\hline Leakage inductance of stator winding $\left(\mathrm{L}_{\mathrm{ls}}\right)$ & 0.005 \\
\hline Resistance of rotor winding $\left(\mathrm{R}_{\mathrm{r}}\right)$ & $0.75 \mathrm{ohm}$ \\
\hline Leakage inductance of rotor winding $\left(\mathrm{L}_{\mathrm{lr}}\right)$ & 0.0052 \\
\hline Mutual inductance of windings $\left(\mathrm{L}_{\mathrm{m}}\right)$ & $0.1254 \mathrm{H}$ \\
\hline Inertia $(\mathrm{J})$ & $0.0018 \mathrm{kgm}^{2}$ \\
\hline
\end{tabular}

